\title{
Top Management Team Heterogeneity, Shareholding Proportion of the Largest Shareholder and Innovation Performance: A Study Based on a Panel Smooth Transition Regression Model
}

\author{
Yueying Lin \\ School of Business Administration South China University of Technology, Guangzhou, China \\ Email: adwein li@scut.edu.cn
}

How to cite this paper: Lin, Y.Y. (2018) Top Management Team Heterogeneity, Shareholding Proportion of the Largest Shareholder and Innovation Performance: A Study Based on a Panel Smooth Transition Regression Model. Open Journal of Business and Management, 6, 60-76. https://doi.org/10.4236/ojbm.2018.61005

Received: August 18, 2017

Accepted: January 5, 2018

Published: January 8, 2018

Copyright $\odot 2018$ by authors and Scientific Research Publishing Inc. This work is licensed under the Creative Commons Attribution International License (CC BY 4.0).

http://creativecommons.org/licenses/by/4.0/

\section{Open Access}

\begin{abstract}
Research highlights the role of the shareholding proportion of the largest shareholder (TOP1) in the relationship of top management team (TMT) heterogeneity and corporate innovation performance. The empirical study makes use of a panel smooth transition regression model (PSTR) to investigate the nonlinear relationship between top management team (TMT) heterogeneity and corporate innovation performance in listed companies of household appliance industry. Data from a sample of 18 China listed household appliance industry from 2004-2014 provides us with a good opportunity to explore empirical evidences for the relationship. Following this idea, we propose to detect innovation performance by focusing on the proportion of the largest shareholder. We reveal that as the shareholding proportion of the largest shareholder becomes different, a nonlinear transition is found in relationship between TMT heterogeneity and innovation performance. The result shows that the model is divided into low regime and high regime at the point of TOP $1=0.3144$. Since equity structure and equity concentration varies in different regimes, the influence of TMT heterogeneity on corporate innovation performance has nonlinear changes as well.
\end{abstract}

\section{Keywords}

TMT Heterogeneity, Shareholding Proportion of the Largest Shareholder, Range Effect, Nonlinear, Innovation Performance, Panel Smooth Transition Regression Model 


\section{Introduction}

Since Hambrick and Masonproposed Upper Echelon Theory, there have been many researches focused on the theory [1]. Scholars generally hold that corporate sustainable development not only depends on a single person, but also is achieved by top management team (TMT) that consists of members having different characteristics, skills, educational backgrounds and social experiences. In order to make more all-sided and in-depth analysis on TMT characteristics as well as their influence on corporate, the concept of heterogeneity, which is used to measure the convergence of knowledge and capabilities and members' specific characteristics caused by the difference of members' characteristics (including demographic characteristics, cognitive difference, social values and work experience), is introduced into TMT researches. As TMT members' values and cognitive abilities are difficult to be measured directly, scholars in empirical studies use demographic characteristics (age, tenure and educational background) and their heterogeneity as substitute variables to investigate TMT influences on strategic decisions and performance, for example, Pelled chose educational background heterogeneity [2] and Jehnchose information heterogeneity [3].

With the new economic era coming, competition among corporations becomes stronger under the rapid and complicated environmental change. Therefore, the focus in theoretical fields and business circles is shifted to the formation and development of corporate dynamic competitive capabilities, and TMT is the important driving force of corporate creativity and innovative capabilities. Given that, this study analyzes data of 18 listed companies in China appliance industry from 2004-2014 to investigate the nonlinear relationship between TMT heterogeneity (education, age and tenure) and innovation performance under different shareholding proportions of the largest shareholder, by use of panel smooth transition regression models (PSTR) of Gonzalez et al. [4].

The PSTR model not only reflects cross-section heterogeneous changes of panel data effectively, but also allows model parameters to change in a smooth, nonlinear manner as the transition variables change, which explores whether the relationship between TMT heterogeneity and corporate innovation performance exhibits nonlinear changes in response to changes in shareholding proportion of the largest shareholder. This study's findings may guide efforts to improve the methodological rigor of future studies that will use panel smooth transition regression model (PSTR) as are search strategy, resulting in greater reliability and validity for the results of studies. Furthermore, this study aims to add to the literature by providing evidence about how the shareholding proportion of the largest shareholder influence the relationship of top management team (TMT) heterogeneity and corporate innovation performance.

This study is organized as follows. In Section 2, research conducts a review of the literature on the relationship of the TMT heterogeneity and corporate innovation. The details of panel smooth transition regression models (PSTR) are presented in Section 3. This paper performs the empirical tests in Section 4. In 
Section 5, it provides a summary and discussion about this work.

\section{Literature Review}

In this section, this study first reviews the prior research work on the relationship of the TMT heterogeneity and corporate innovation. Based on the context, it points out that there is rare in-depth research on relationship between TMT and corporate innovation.

Hambrick, Cho and Chen found that TMT heterogeneity was positively related with corporate behavior disposition, strategic significance and scale [5]. TMT collective capabilities of strategic formulation and structural reaction are regarded as the effective ways facing with business environment complexity [6]. A lot of research results show that, the higher TMT educational level is, the more scientific and comprehensive decisions are, which contributes to more corporate innovation [1]. The researches on relationship between TMT heterogeneity and innovative performance have achieved fruitful results. In the early 1980s, since educational levels of top managers improved the capabilities of opportunity recognition and judgment as well as capabilities of information processing that helped to discover innovation opportunities, market innovation in American airlines was owed to TMT heterogeneity [7]. However, other results show negative influence of TMT heterogeneity on corporate innovation. O'Relly, Snyder and Boo the found that TMT heterogeneity was negatively related with dynamic adaptive capabilities when they researched on electronic companies [8]. Contradictions from communication in heterogeneous teams reduce decision efficiency, so heterogeneity even makes the origin of communicative obstruction and conflicts. Hambrick et al. found that TMT heterogeneity was negatively related with speed of corporate behavioral implementation [5]. Besides, Zhao Bingyan et al. studied the influence of TMT structural differences on innovation performance and the impaction of team reflexivity by collecting the samples from 96 high-tech enterprises in Yangtze River delta region. And they concluded that the TMT heterogeneity of education, tenure and professional background have positive effects on innovation performance while the team reflexivity enhancing the action in this course [9].

Previous researches are focused on whether TMT can support corporate innovation, but there is rare in-depth research on relationship between TMT and corporate innovation. Carpenter proposed that corporate strategy or social environment variables should be introduced into the relationship between TMT and corporate performance [10]. For example, organizational characteristics and environmental characteristics should be considered in researches on relationship between TMT heterogeneity and innovation performance. Equity structure that reflects investors' position in corporate decisions influences corporate performance through governance mechanism. JA Krug and WH Hegarty found that the different types of executives were found to be an important predictor of firm innovation performance in certain acquisition categories [11]. Jakub Kastl, Da- 
vid Martimort and Salvatore Piccolo took Italian manufacturing listed companies as samples, and found that operators were more inclined to make long-term strategic decisions and showed more positive attitude toward $\mathrm{R} \& \mathrm{D}$ input as more centralized ownership alleviated interest conflicts between operators and owners [12]. Sanghoon Lee took Korean listed companies as research subjects, by use of fixed-effect feasible generalized least squares(FGLS) regression model and dynamic gaussian mixture model(GMM) regression model, to analyze the influence of equity concentration on R\&D input, the result of which showed equity concentration positively affected R\&D input [13]. Jackie Di Vito, Claude Laurin and Yves Bozec found that highly centralized equity negatively affected $\mathrm{R} \& \mathrm{D}$ input by study on Canadian manufacturing listed companies, which is same as the results of Yafeh and Yosha [14] [15]. La Porta found that shareholding balance contributed to $\mathrm{R} \& \mathrm{D}$ input, as the balance situation made up of several large shareholders can effectively control the impact of individual interest on R\&D input decision [16]. Besides, Xuangang Lvstudies the relationship between shareholding ratio and capital occupation of listed companies inconsideration of the difference of capital structure of the company. The results show that there is a significant interval effect between the proportion of controlling shareholders and capital occupation of listed companies. It means that different shareholding ratios have different effects on performance [17].

The Industrial Research Institute proposed that the all growth in global R\&D investments in being driven by substantial increases in Asian countries and especially in China, which for many years increased its R\&D investments by more than $10 \%$ per year [18]. Liu Shengqiang and Liu Xing found that R\&D input turned out to decrease first and then increase with the shareholding proportion of the largest shareholder going up, by taking A Share Manufacturing Listed Companies from 2002 to 2008 as samples and using mixed data regression and panel data model [19]. Bai Yixin et al. confirmed that there was an inverted U-shape relationship between shareholding proportion of the largest shareholder and R\&D input based on panel data Vogt model [20]. Wen Fang proposed that there was interval effect and cubic curvilinear relationship between shareholding proportion of controlling shareholders and R\&D input by study on China listed companies from 1999 to 2006 [21]. Feng Genfu and Wen Junmade an empirical research by use of listed companies data from 2005 to 2007, and concluded that there was a $U$-shape relationship between equity concentration and technological innovation [22]. Yu Taotook A share manufacturing companies listed in Shanghai and Shenzhen as research subjects, and found that equity concentration had no influence on R\&D investment activities through multiple regression [23]. Xin Jun et al. found that China's technology innovation has an obvious spatial autocorrelation [24]. Besides, Yang Jianjun and Sheng Suoconcluded that equity concentration was negatively related with technological innovation in ways of questionnaire [25].

From literature review, there is rare in-depth research on relationship between 
TMT and corporate innovation, ignoring the effect of equity structure between team member and innovation performance. Despite the paucity of empirical research, the literature indicates that shareholding proportion of the largest shareholder can significantly influence the relationship. At the same time, enterprise decision-making and collaboration won't show a fixed percentage or causal relationship, but it is usually characterized by a nonlinear feedback. And, the relationship between TMT heterogeneity and innovation performance will be a nonlinear relationship with the dynamic change of shareholding proportion of the largest shareholder. Moreover, the role of shareholding proportion of the largest shareholder has become an important research direction in the field of strategic management. Given the above observation, the empirical study makes use of a panel smooth transition regression model (PSTR) to investigate the nonlinear relationship between top management team (TMT) heterogeneity and corporate innovation performance in listed companies of household appliance industry.

\section{Panel Smooth Transition Regression Model}

In order to investigate whether the relationship between TMT heterogeneity and corporate innovation performance exhibits nonlinear changes with changes in shareholding proportion of the largest shareholder, this study uses PSTR model of Gonzalez et al. to make an in-depth analysis of the nonlinear changes in relationship between TMT heterogeneity and innovation performance. This model, which is the expansion of panel threshold regression (PTR) model [26], not only reflects cross-section heterogeneous changes of panel data effectively, but also allows model parameters to change in a smooth, nonlinear manner as the transition variables change. A PSTR model with a transition variable is defined as follows:

$$
y_{t}=\mu_{i}+\beta_{0}^{\prime} x_{i t}+\beta_{1}^{\prime} x_{i t} g\left(q_{i t} ; \gamma, c\right)+\varepsilon_{i t}
$$

for $i=1,2 \cdots N$, and $t=1,2 \cdots T$, where $N$ and $T$ respectively represent the cross-section and time dimensions of the panel. Explained variable $y$ it is a scalar, and explanatory variable $x$ it is a k-dimensional column vector. While $\mu_{i}$ refers to the fixed effect, $\varepsilon$ it is the residual. The transition function $g\left(q_{i t} ; \gamma, c\right)$ is the continuous function of the transition variable $q_{i t}$ and is normalized to be bounded between 0 and 1 . The logistic specification is:

$$
g\left(q_{i t} ; \gamma, c\right)=\left\{1+\exp \left(-\gamma \prod_{j=1}^{m}\left(q_{i t}-c_{j}\right)\right)\right\}^{-1}
$$

where: $\gamma>0, c_{1} \leq c_{2} \leq \cdots \leq \mathrm{cm}$. The parameter $\gamma$ determines the smoothness of the transitions; $\mathrm{c}$ is the location parameter; and $\mathrm{m}$ generally equals 1 or 2 . As Figure 1 shows, when $m=1$, the transition function is a logistic one that monotonically increases with the transition variable qit. When $g\left(q_{i t} ; \gamma, c\right)=0$, model (1) is called the low regime; when $g\left(q_{i t} ; \gamma, c\right)=1$, it is called the high regime. As the value of the transition function changes smoothly between 0 and 1 , the model (1) changes smoothly between the high and low regimes at transition point $c$. 


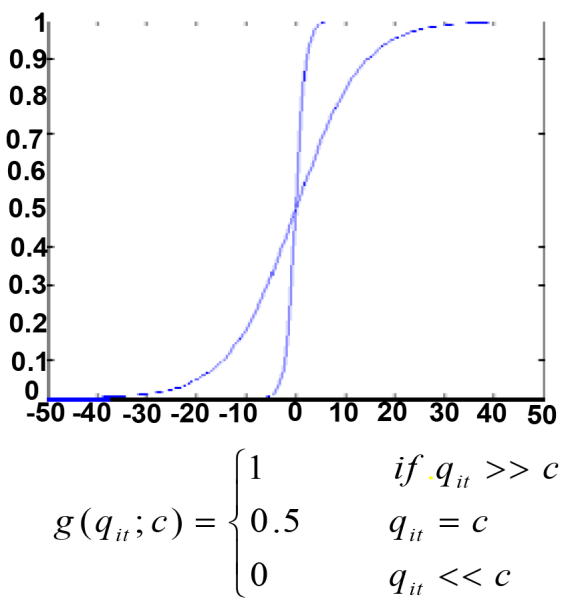

Figure 1. Graph of the transition function when $m=1$.

The corresponding explanatory variable coefficient also changes between $\beta_{0}$ and $\beta_{0}+\beta_{1}$ as $q_{i t}$ increases, where the change is centered at $c$.

As Figure 2 shows, when $m=2$, the transition function is indexical, and model (1) is divided into two outer regimes and one middle regime in which the transition function has its smallest value at $(\mathrm{c} 1+\mathrm{c} 2) / 2$. When $g\left(q_{i t} ; \gamma, c\right)=1$, model (1) is called the outer regime; when $g\left(q_{i t} ; \gamma, c\right)=0$, it is called the middle regime.

When $\gamma \rightarrow \infty$ and $m=1$, the transition function turns into indicative function, and PSTR model turns into PTR model of two regimes; when $\gamma \rightarrow \infty$ and $m=2$, PSTR model turns into PTR model of three regimes that include two same outer regimes and one middle regimes. When $q_{i t}=c$ or $\gamma \rightarrow 0$, $g\left(q_{i t} ; \gamma, c\right)=0.5$, and PSTR model degenerates into a linear fixed effect model.

A homogeneity test should be conducted to determine whether the correlation among variables is linear before using a PSTR model to make estimations. If homogeneity is rejected, the PSTR model can be used for estimation; otherwise, a linear model should be constructed. A homogeneity test is usually conducted by testing the null hypothesis $\mathrm{H}_{0}: \gamma=0$ or $\mathrm{H}_{0}: \beta_{1}=0$, but the PSTR model contains unidentified nuisance parameters under both of these hypotheses. Hence, this study, following Luukkonen et al. [27] [28], uses first-order Taylor expansion around $\gamma=0$ of the transition function instead to solve the identification problem, which leads to the following auxiliary regression:

$$
y_{i t}=\mu_{i}+\alpha_{0} x_{i t}+\alpha_{1} x_{i t} q_{i t}+\varepsilon_{i t}
$$

Thereby, testing $H_{0}: \gamma=0$ equals to testing $H_{0}: * 0=* 1=0$. If the null hypothesis is rejected, the model will prove to be a PSTR model with at least one transition function.

After homogeneity is rejected, the value of $m$ in the transition function needs to be determined. Since most situations have been considered in condition of $m$ $=1$ or $m=2$, Granger and Terasvirta (1993) conducted a first-order Taylor expansion to model (1) at $\gamma=0$ to determine the final value of $\mathrm{m}$, which constructed the following three test hypotheses [29]: 


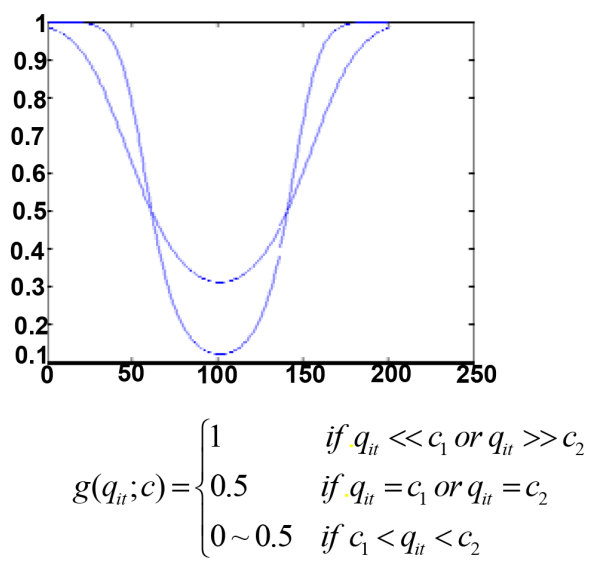

Figure 2. Graph of the transition function when $m=2$.

$$
H_{03}: \beta_{3}=0, H_{02}: \beta_{2}=0\left|\beta_{3}=0, H_{01}: \beta_{1}=0\right| \beta_{2}=\beta_{3}=0
$$

The condition of $m=1$ is applied except for the strongest rejection of $H_{02}$ that suggests $m=2$ to be applied [29] [30]. Based on the above analysis, as PSTR model is constructed to investigate the nonlinear relationship between TMT heterogeneity and corporate performance, the correlation coefficient $\beta$ can be expressed as:

$$
\beta=\frac{\partial y}{\partial x}=\beta_{0}+\beta_{1} g\left(q_{i t} ; \gamma, c_{j}\right)
$$

When $m=1$, the sign of coefficient $\beta_{1}$ reflects the transition trend of correlation coefficient $\beta$ in relationship between TMT heterogeneity and corporate performance with the change of $q_{i t}$ value. Specifically, when $\beta_{1}$ presents plus sign, $\beta$ value increases as $q_{i t}$ value increases; when $\beta_{1}$ presents minus sign, $\beta$ value decreases as $q_{i t}$ value increases.

\section{Study Design}

\subsection{Sample Selection}

Research data in this study is collected from China Stock Market Trading Database (CSMAR), Gildata and corporate annual statements. The companies of household appliance industry listed in A share Shanghai and Shenzhen exchanges during 2004-2014 are selected as research samples. This study filters the samples as follows: samples with delist during research period or data deficiencies are eliminated; samples with financial problems or ST are eliminated. Finally, this study obtains a balanced panel data set with the number of cross-section $N=18$ and the time series $T=11$ for a total of 198 valid observed values.

\subsection{Variables Definition}

In order to investigate that whether the relationship between TMT heterogeneity and corporate innovation performance exhibits nonlinear changes with changes in shareholding proportion of the largest shareholder, this study takes corporate 
innovation performance as explained variable, TMT heterogeneity as explanatory variable, shareholding proportion of the largest shareholder as transition variable, as well as firm age, firm size, and asset-liabilities ratio as control variables. The operational definitions of variables are as follows:

There are different definitions of TMT in present literature. Hambrick et al. proposed that TMT consisted of vice-president and the above titles [5]. Elron hold that TMT only included CEO and senior vice-presidents. According to China listed corporation regulation, this study defines TMT as vice-president, deputy general manager, chief accountant, chief economist, chief financial officer, chief engineer and other top managers above these titles [31].

\subsubsection{Explained Variable}

As amount of the application for patent reflects the capabilities of corporate innovation, the corporate that keeps stronger innovative capabilities has more applications for patent. Therefore, this study selects amount of the application for patent to measure corporate innovation performance. Considering the original data may exaggerate the exceptional situation, this study uses natural logarithm of patent applications.

\subsubsection{Explanatory Variable}

This study selects differences in educational level, tenure and age to measure TMT heterogeneity, which is used most generally and frequently [10] [32] [33]. The Herfindal-Hirschman coefficient (also called the Blau coefficient) is calculated for educational level heterogeneity (HEDU) by use of the formula $H=1-\sum_{i=1}^{n} P_{i}^{2}$, where $p_{i}$ refers to the ratio of i-type members in the group, and the value of $H$ is between 1 and 0 . The value of $H$ approaching 1 means higher heterogeneity; the value of $H$ approaching 0 means higher homogeneity among TMT members. Allison compared different measures, and proposed that coefficient of variation (the ratio of the standard deviation to the mean) as a measure of invariable ratio should be better than standard deviation and variance in measuring continuous variables (such as age and tenure) [1] [34]. Hence, this study uses coefficient of variation to measure age heterogeneity (HAGE) and tenure heterogeneity (HTEN).

According to the subject classifications of the Chinese Ministry of Education and classifications used in the existing literature, this study divides TMT educational levels into 5 categories: technical secondary or below, junior college, undergraduate, master degree and doctor degree.

\subsubsection{Transition Variable}

This study takes the shareholding proportion of the largest shareholder as the transition variable.

\subsubsection{Control Variable}

Firm age (AGE), firm size (SIZE), and asset-liabilities ratio (DEBT) are selected 
as control variables. Corporate age is calculated by the observed year minus the foundation year; corporate size is calculated by the natural logarithm of total assets; asset-liabilities ratio is calculated by total liabilities divided by total assets. Table 1 shows the descriptive statistics results of each variable, including 198 observed values of 18 sample companies in 11 years.

\subsection{Panel Data Unit Root Test}

Gonzalez's PSTR model requires variables smooth to avoid spurious regression. The first generation unit root tests that hypothesize cross-sectional independence do not take structural transition factors into consideration. A unit root test without consideration of structural transition factors often makes the null hypothesis of a unit root easily accepted. Therefore, structural transition factors should be considered. As a result, the second generation unit root tests, which take the cross-section dependence into consideration, should be used for robustness. This study conducts the panel unit root tests of Moon and Perron, and Choi. As shown in Table 2, the null hypothesis of unit root is rejected for all variables, which means each variable of this model is smooth.

\subsection{Homogeneity Test and Determination of $\mathrm{m} / \mathrm{r}$ Values}

This study used the Lagrange multiplier test (LM) (chi-square distribution), Lagrange multiplier F-test (LMF) (F-distribution) and likelihood ratio test (LRT) (T-distribution) to test homogeneity and ensure the robustness. The results in Table 3 show that LM, LMF and LRT tests all reject the null hypothesis of homogeneity at the level of $1 \%$, which means there is a nonlinear relationship

Table 1. Descriptive statistics results.

\begin{tabular}{lccccc}
\hline \multicolumn{1}{c}{ Variable } & Code & Mean & $\begin{array}{l}\text { Standard } \\
\text { deviation }\end{array}$ & Skewness & Kurtosis \\
\hline Age heterogeneity & HAGE & 0.17 & 0.36 & 0.38 & 0.42 \\
Education heterogeneity & HEDU & 0.63 & 0.79 & -0.43 & 0.30 \\
Tenure heterogeneity & HTEN & 0.42 & 0.33 & 0.51 & -0.32 \\
Firm size & SIZE & 22.45 & 1.30 & 0.35 & -0.29 \\
Firm age & AGE & 20.06 & 10.09 & 1.45 & 0.93 \\
Asset-liabilities ratio & DEBT & 0.59 & 0.20 & -0.07 & 2.96 \\
$\begin{array}{l}\text { Patent applications } \\
\text { Shareholding proportion of the }\end{array}$ & TOP1 & 0.33 & 0.14 & -0.22 & -1.03 \\
largest shareholder & & 3.5 & 2.18 & 0.62 & -0.02 \\
\hline
\end{tabular}

Table 2. Results of panel data unit root test.

\begin{tabular}{|c|c|c|c|c|c|c|c|c|}
\hline & HAGE & HEDU & HTEN & SIZE & AGE & DEBT & PAT & TOP1 \\
\hline $\mathrm{MP}(\mathrm{taB})$ & $-4.736^{\star * *}$ & $-5.472^{\star * \star}$ & $-7.349^{\star * *}$ & $-4.245^{\star * *}$ & $-15.760^{* * *}$ & $-4.095^{\star * *}$ & $-5.107^{\star * *}$ & $-4.272^{\star * *}$ \\
\hline Choi(Pm) & $3.446^{* * *}$ & $4.806^{* * *}$ & $11.865^{\star * *}$ & $2.838^{* * *}$ & $10.303^{* * *}$ & $6.071^{\star * *}$ & $4.319^{* * *}$ & $6.017^{* * *}$ \\
\hline
\end{tabular}

Note: ${ }^{\star} \mathrm{p}<0.1 ;{ }^{* *} \mathrm{p}<0.05 ;{ }^{* *} \mathrm{p}<0.01$, two-tailed test. 
Table 3. Homogeneity test.

\begin{tabular}{ccc}
\hline \multicolumn{3}{c}{$H_{0}$ : linear model $H_{1}$ : PSTR model that has at least one threshold value } \\
\hline \multicolumn{3}{r}{ Transition Variable: shareholding proportion of the largest shareholder } \\
\hline & Statistics & P-value \\
\hline Wald Tests (LM) & $41.080^{* * *}$ & 0.001 \\
Fisher Tests (LMF) & $2.356^{* * *}$ & 0.002 \\
LRT Tests (LRT) & $46.041^{* * *}$ & 0.000 \\
\hline
\end{tabular}

Note: ${ }^{*} \mathrm{p}<0.1 ;{ }^{* *} \mathrm{p}<0.05 ;{ }^{* * *} \mathrm{p}<0.01$, two-tailed test.

between TMT heterogeneity and corporate innovation performance. As with model (1), this study constructs following PSTR model:

$$
P A T_{i t}=\mu_{i}+\beta_{0}^{\prime} x_{i t}+\beta_{1}^{\prime} x_{i t} g\left(T O P 1_{i t} ; \gamma, c\right)+\varepsilon_{i t}
$$

$X_{i t}$ refers to explanatory variables including age heterogeneity, educational level heterogeneity and tenure heterogeneity as well as control variables including firm age, firm size and asset-liabilities ratio.

As the heterogeneity is confirmed, this study follows Granger and Terasvirta to conduct first-order Taylor expansion around $\gamma=0$ of the transition function in model (4), and constructs the auxiliary regression to determine $m$ value, the results of which are showed in Table 4.

According to Granger and Terasvirta, it is generally sufficient to consider $m=1$ or $m=2$. The condition of $m=1$ is applied except for the strongest rejection of $H_{02}$ that suggests $m=2$ to be applied. From Table 4 it is known that $H_{02}$ is not the strongest rejected hypothesis which leads to $m=1$ selected in PSTR model. Namely, the transition function monotonically increases as $q_{i t}$ increases, and model (4) is divided into high and low regimes, in which the explanatory variable coefficient transits between $\beta_{0}$ and $\beta_{0}+\beta_{1}$ centering around $c$ with $q_{i t}$ changing.

\subsection{Parameter Estimation}

The estimation results of model parameter in Table 5 show that the model is divided into high and low regimes in which threshold value is $c=0.3144$ and transition slope is $\gamma=552.7579$. It is known that there is a structural transition in model at the point of TOP $1=0.3144$ and the corresponding function graph is shown as Figure 1. Consequently, the results in Table 5 lead to the complete PSTR model about the nonlinear relationship between TMT heterogeneity and corporate innovation performance:

$$
\begin{aligned}
& P A T_{i t}=\mu_{i}+\beta_{0} x_{i t}+\beta_{1} x_{i t} g\left(T O P 1_{i t} ; 552.7579 ; 0.3144\right)+\varepsilon_{i t} \\
& \beta_{0}=(-0.2135,-4.3877,0.4038,0.4652,-0.0154,0.1064) \\
& \beta_{1}=(-7.0791,1.8784,-0.4462,-0.0856,0.0161,-0.0032) \\
& x_{i t}=\left(H A G E_{i t}, H E D U_{i t}, H_{T E N}, \text { SIZE }_{i t}, D E B T_{i t}, A G E_{i t}\right)
\end{aligned}
$$

When TOP1 $<0.3144$, the model is in a low regime (Figure 3). When TOP1 > 0.3144 , the model is in a high regime. In the low regime, there is an insignificant 
Table 4. Determination of $\mathrm{m}$ value in the model.

\begin{tabular}{ccc}
\hline \multicolumn{3}{c}{ When the rejection of $H_{02}$ is the strongest, select $m=2$; otherwise, select $m=1$} \\
\hline$H_{03}: \beta_{3}=0$ & Statistic & P-Value \\
$H_{02}: \beta_{2}=0 \mid \beta_{3}=0$ & 0.954 & 0.516 \\
$H_{01}: \beta_{1}=0 \mid \beta_{2}=\beta_{3}=0$ & 0.379 & 0.990 \\
\end{tabular}

Note: ${ }^{*} \mathrm{p}<0.1{ }^{* *} \mathrm{p}<0.05 ;{ }^{* *} \mathrm{p}<0.01$, two-tailed test.

Table 5. Descriptive statistics results.

\begin{tabular}{|c|c|c|c|c|}
\hline & $\beta_{0}$ & T-value & $\beta_{1}$ & T-value \\
\hline HAGE & -0.2135 & -0.0887 & $-7.0791^{*}$ & -1.8293 \\
\hline HEDU & $-4.3877^{* * *}$ & -2.8431 & 1.8784 & 1.0365 \\
\hline HTEN & $0.4038^{*}$ & 1.8247 & -0.4462 & -1.4028 \\
\hline SIZE & $0.4652 * * *$ & 3.6476 & -0.0856 & -1.1683 \\
\hline DEBT & $-0.0154^{* * *}$ & -2.7227 & $0.0161^{* *}$ & 1.9953 \\
\hline AGE & $0.1064^{* * *}$ & 3.9542 & -0.0032 & -0.2181 \\
\hline Threshold value $c$ & \multicolumn{4}{|c|}{0.3144} \\
\hline Slope parameter $\gamma$ (Transition slope) & \multicolumn{4}{|c|}{552.7579} \\
\hline
\end{tabular}

Note: ${ }^{*} \mathrm{p}<0.1,{ }^{* *} \mathrm{p}<0.05,{ }^{* *} \mathrm{p}<0.01$, two-tailed test.

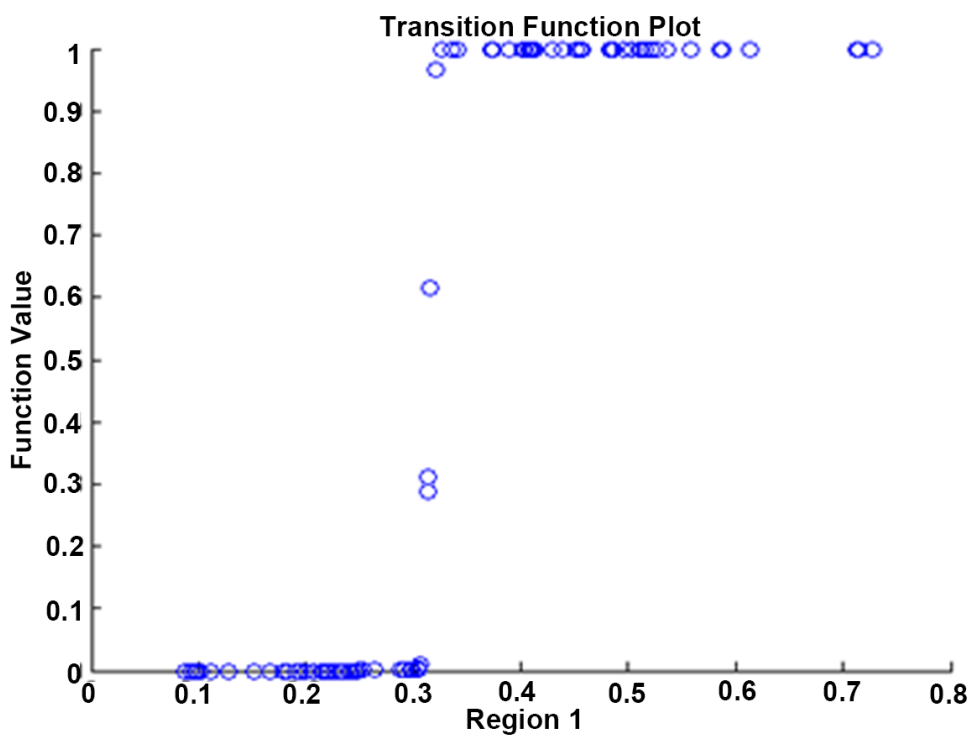

Figure 3. Graph of transition function

correlation between age heterogeneity and corporate innovation performance; in the high regime, there is a significant negative correlation between age heterogeneity and corporate innovation performance $\left(\beta_{0}+\beta_{1}=-7.2926, \mathrm{p}<0.1\right)$. In the low regime, there is a significant negative correlation between educational level heterogeneity and corporate innovation performance $\left(\beta_{0}=-4.3877, \mathrm{p}<0.05\right)$; 
in the high regime, there is an insignificant correlation between educational level heterogeneity and corporate innovation performance. Thus, the correlation between educational level heterogeneity and corporate innovation performance changes at the point of $T O P 1=0.3144$, demonstrating a nonlinear relationship. In the low regime, there is a significant positive correlation between tenure heterogeneity and corporate innovation performance $\left(\beta_{0}=0.4038, \mathrm{p}<0.1\right)$; in the high regime, there is an insignificant correlation between tenure heterogeneity and corporate innovation performance. Thus, the correlation between tenure heterogeneity and corporate innovation performance changes at the point of $T O P 1=$ 0.3144 , demonstrating a nonlinear relationship. As above, the relationship between TMT heterogeneity and corporate innovation performance exhibits nonlinear changes with changes in shareholding proportion of the largest shareholder, which supports the hypothesis.

\section{Conclusions and Discussion}

This study uses PSTR model developed by Gonzalez et al. to investigate the nonlinear relationship between TMT heterogeneity and corporate innovation performance in household appliance industry, which allows nonlinear transition of the regression coefficient as transition variables (shareholding proportion of the largest shareholder) change. The research results show that the model is divided into low regime and high regime at the point of TOP $1=0.3144$. When TOP $1<$ 0.3144 , the model is in a low regime. When TOP1 $>0.3144$, the model is in a high regime. Since equity structure and equity concentration vary in different regimes, the influence of TMT heterogeneity on corporate innovation performance has nonlinear changes as well. The conclusions of this study are as follows:

When the shareholding proportion of the largest shareholder is below 0.3144 , the power of large shareholders is restrict and there are supervisions and balances among shareholders. The TMT members who have heterogeneous educational levels have experienced different growing environments and educational modes which lead to heterogeneous values and behavioral manners. Therefore, TMT with higher educational level heterogeneity has more specified labor division in the process of innovation investment and technological update strategies formulation. The educational level heterogeneity makes members too caught in controversies to miss development opportunities and has no contribution to innovation performance in the low regime where power among shareholders keeps balanced. The TMT members whose tenures experience different development stages and events in companies have interpretations to organizations and strategies [35]. With different reactions and interpretations to the external and internal environments, various capabilities which make full use of social network to obtain resources and supports and formulate diversified strategies [36], tenure heterogeneity provides more opportunities to transform the original management modes and reconstruct strategies [37]. Tihanyi et al. (2000) found that 
TMT with high tenure heterogeneity could control risks and uncertainties with rich social experiences and business practices to push corporate forward [38]. Since the tenures of TMT members influence coordination and operation, and further affect decision scientificity and efficiency, Srivastava and Lee pointed that TMT with higher tenure heterogeneity would produce new products more quickly and promote technological accumulation to lead to industrial development [39]. In the low regime where shareholders keep balanced, TMT with high tenure heterogeneity has more comprehensive knowledge of developing stages, which helps to take innovation strategies.

When the shareholding proportion of the largest shareholder is higher than 0.3144 , the controlling status of the controlling shareholders becomes firmer. In China, as listed companies have highly centralized equity, state-owned shareholding proportion of the largest shareholder is much higher than the sum of that of the second to the fifth largest shareholders, which lead to little voice and influence of other shareholders. As age presents a manger's experiences and inclination to bear risks, age heterogeneity reflects members' differences in experiences that is closely related to managerial experience, innovative awareness, learning and adaptive capabilities. Since TMT with low age heterogeneity have similar experiences, values, behavioral manners and strategic choices, the team usually has more cohesiveness and less sentimental conflicts to reach agreements and strategic decisions with high efficiency. Therefore, the high shareholding proportion of the largest shareholder contributes to innovation decisions formulation. However, TMT with high age heterogeneity have various views, cognitive levels and values on same things. Members with high age heterogeneity may make decisions against corporate innovation and long-term development out of the largest shareholder's interests in front of complex economic environment and violent competition.

This study analyzes panel data from 18 China listed companies in Shanghai and Shenzhen exchanges in 11 consistent years, by use of PSTR model to investigate the nonlinear relationship between TMT heterogeneity and corporate innovation performance. It not only provides a new perspective on TMT researches theoretically and methodologically, and reveals the relationship among TMT, shareholding proportion of the largest shareholder and innovation performance, but also provides practical directions about how to choose TMT members and make innovation decisions for household appliance industry. However, there still are some limitations. First, the measurement of tenure by use of TMT members' duration in their current positions does not accurately reflect TMT's tenure characteristics. Since a TMT member may have had other senior positions in the company before, the measurement of duration in the current position is hard to reflect the cooperation and cohesiveness among TMT members. The total time at the company or total time at the decision-making level can be considered to measure the tenure in future studies. Second, while the shareholding proportion of the largest shareholder is selected as the transition variable, other variables are not considered, such as competitive characteris- 
tics in the industry and differences of external institutional environments, which also have influences on relationship between TMT heterogeneity and corporate performance. Third, household appliance industry is a competitive industry, the characteristics of which are not reflected in this study, as industrial characteristics have influences on relationship between equity concentration and corporate performance.

\section{References}

[1] Hambrick, D.C. and Mason, P.A. (1984) Upper Echelons Organization as a Reflection of Its Managers. The Academy of Management Review, 9, 193-206.

[2] Pelled, L.H. (1996) Demographic Diversity, Conflict, and Work Group Outcomes: An Intervening Process Theory. Organization Science, 7, 615-631. https://doi.org/10.1287/orsc.7.6.615

[3] Jehn, K.A. (1995) A Multimethod Examination of the Benefits and Detriments of Intragroup Conflict. Administrative Science Quarterly, 40, 256-282. https://doi.org/10.2307/2393638

[4] González, A., Terasvirta, T. and Van Dijk, D. (2005) Panel Smooth Transition Regression Models (Vol. 165). School of Finance and Economics, University of Technology.

[5] Hambrick, D.C., Cho, T.S. and Chen, M.J. (1996) The Influence of Top Management Team Heterogeneity on Firms' Competitive Moves. Administrative Science Quarterly, 41, 659-684. https://doi.org/10.2307/2393871

[6] Murray, A.I. (1989) Top Management Group Heterogeneity and Firm Performance. Strategic Management Journal, 10, 125-141. https://doi.org/10.1002/smj.4250100710

[7] Labich, K. (1990) American Takes on the World. Fortune, 122, 40-48.

[8] O’Reilly, C., Snyder, R. and Boothe, J. (1993) Effects of Executive Team Demography on Organizational Change. Organizational Change and Redesign, 147-175.

[9] Zhao, B.Y., Yu-Hui, G.E., Wang, H. and School, B. (2017) Tmt Structural Differences and Innovation Performance: The Moderating Effects of Team Reflexivity. Industrial Engineering \& Management.

[10] Carpenter, M.A. (2002) The Implications of Strategy and Social Context for the Relationship between Top Management Team Heterogeneity and Firm Performance. Strategic Management Journal, 23, 275-284. https://doi.org/10.1002/smj.226

[11] Krug, J.A. and Hegarty, W.H. (2015) Post Acquisition Turnover among U.S. Top Management Teams: An Analysis of the Effects of Foreign vs. Domestic Acquisitions of U.S. Targets. Strategic Management Journal, 18, 667-675. https://doi.org/10.1002/(SICI)1097-0266(199709)18:8<667::AID-SMJ918>3.0.CO;2$\underline{\mathrm{E}}$

[12] Kastl, J., Martimort, D. and Piccolo, S. (2013) Delegation, Ownership Concentration and R\&D Spending: Evidence from Italy. The Journal of Industrial Economics, 61, 84-107. https://doi.org/10.1111/joie.12012

[13] Lee, S. (2012) The Effect of Ownership Concentration on R\&D Decisions in Korean Firms. Seoul Journal of Economics, 25, 89-110.

[14] Di Vito, J., Laurin, C. and Bozec, Y. (2010) R\&D Activity in Canada: Does Corporate Ownership Structure Matter? Canadian Journal of Administrative Sciences, 27, 107-121. https://doi.org/10.1002/cjas. 152 
[15] Yafeh, Y. and Yosha, O. (2003) Large Shareholders and Banks: Who Monitors and How? The Economic Journal, 113, 128-146. https://doi.org/10.1111/1468-0297.00087

[16] Porta, R., Lopez-de-Silanes, F. and Shleifer, A. (1999) Corporate Ownership around the World. The Journal of Finance, 54, 471-517. https://doi.org/10.1111/0022-1082.00115

[17] Lv, X. (2017) A Study on the Relationship between the Shareholding Ratio of the Controlling Shareholders and the Capital Occupation under the Different Capital Structures. American Journal of Industrial \& Business Management, 7, 328-340. https://doi.org/10.4236/ajibm.2017.73023

[18] Institute, T.I. (2017) 2017 R\&D Trends Forecast: Results from the Industrial Research Institute's Annual Survey. Research-Technology Management.

[19] Liu, S.Q. and Liu, X. (2010) The Threshold Effect Analysis of Board Size on Corporate $R \& D$ Investment Behavior-Base on Panel Data of Manufacturing and High-Tech Industry Companies. Forecasting.

[20] Bai, Y.X., Liu, X. and An, L. (2008) The Influence of Ownership Structure on R\&D Investment Decision. Statistics and Decision Making, 5, 131-134.

[21] Wen, F. (2008) Ownership Concentration, Outside Blockholders, and R\&D Expenditure: Evidence from China's Listed Companies. China Journal of Economics, 25, 787-792.

[22] Feng, G.F. and Wen, J. (2008) An Empirical Study on Relationship between Corporate Governance and Technical Innovation of Chinese Listed Companies. China Industrial Economics, 7, 91-101.

[23] Yu, T. (2012) Impact of Corporate Governance Structure on R\&D Investments: Empirical Data from Listed Manufacturing Companies. Communication of Finance and Accounting, 1, 91-93.

[24] Xin-Jun, L.V., Dai, C.X., Economics, S.O. and University, H. (2017) R\&D Input Heterogeneity and Regional Technology Innovation Spillover Effects. Economic Survey.

[25] Jian-jun, Y.A.N.G. and Sheng, S. (2007) An Empirical Study of the Effects of Corporate Ownership Structure on Technological Innovation Input. Studies in Science of Science, 4, 787-792.

[26] Hansen, B.E. (1999) Threshold Effects in Non-Dynamic Panels: Estimation, Testing, and Inference. Journal of Econometrics, 93, 345-368.

[27] Luukkonen, R., Saikkonen, P. and Teräsvirta, T. (1988) Testing Linearity against Smooth Transition Autoregressive Models. Biometrika, 75, 491-499. https://doi.org/10.1093/biomet/75.3.491

[28] Luukkonen, R., Saikkonen, P. and Teräsvirta, T. (1988) Testing Linearity in Univariate Time Series Models. Scandinavian Journal of Statistics, 161-175.

[29] Granger, C.W. and Terasvirta, T. (1993) Modelling Non-Linear Economic Relationships.OUP Catalogue.

[30] Teräsvirta, T. (1994) Specification, Estimation, and Evaluation of Smooth Transition Autoregressive Models. Journal of the American Statistical Association, 89, 208-218.

[31] Elron, E. (1998) Top Management Teams within Multinational Corporations: Effects of Cultural Heterogeneity. The Leadership Quarterly, 8, 393-412.

[32] Knight, D., Pearce, C.L., Smith, K.G., Olian, J.D., Sims, H.P., Smith, K.A. and Flood, 
P. (1999) Top Management Team Diversity, Group Process, and Strategic Consensus. Strategic Management Journal, 20, 445-465.

https://doi.org/10.1002/(SICI)1097-0266(199905)20:5<445::AID-SMJ27>3.0.CO;2-V

[33] Wei, L.Q. and Wang, Z.H. (2002) Empirical Study on China Listed Corporate Top Management Characteristics and Corporate Performance. Nankai Business Review, 4, 16-22.

[34] Allison, P.D. (1978) Measures of Inequality. American Sociological Review, 865-880. https://doi.org/10.2307/2094626

[35] Katz, R. (1982) The Effects of Group Longevity on Project Communication and Performance. Administrative Science Quarterly, 81-104.

https://doi.org/10.2307/2392547

[36] Dutton, J.E. and Duncan, R.B. (1987) The Creation of Momentum for Change through the Process of Strategic Issue Diagnosis. Strategic Management Journal, 8, 279-295. https://doi.org/10.1002/smj.4250080306

[37] Fan, M. and Jiao, L.B. (2011) TMT Characteristics, TMT Heterogeneity and Corporate Performance. Commercial Times, 23, 97-99.

[38] Tihanyi, L., Ellstrand, A.E., Daily, C.M. and Dalton, D.R. (2000) Composition of the Top Management Team and Firm International Diversification. Journal of Management, 26, 1157-1177. https://doi.org/10.1177/014920630002600605

[39] Srivastava, A. and Lee, H. (2005) Predicting Order and Timing of New Product Moves: The Role of Top Management in Corporate Entrepreneurship. Journal of Business Venturing, 20, 459-48. 


\section{Appendix}

The resource of sample selection.

\begin{tabular}{ll}
\hline Stock code & \\
\hline 000016 & KONKA GROUP CO., LTD. \\
000100 & TCL CORPORATION \\
000404 & HUAYI COMPRESSOR CO., LTD. \\
000521 & HEFEI MEILING CO., LTD. \\
000533 & GUANGDONG MACRO CO., LTD \\
000651 & GREE ELECTRIC APPLIANCES, INC. OF ZHUHAI \\
000810 & SKYWORTH DIGITAL CO., LTD. \\
000921 & HISENSE KELON ELECTRICAL HOLDINGS CO., LTD. \\
002011 & ZHEJIANG DUN'AN ARTIFICIAL ENVIRONMENT CO., LTD \\
002032 & ZHEJIANG SUPOR CO.,LTD \\
002035 & VATTI CORPORATION LIMITED \\
002050 & ZHEJIANG SANHUA CO., LTD. \\
600060 & HISENSE ELECTRIC CO., LTD. \\
600336 & AUCMA COMPANY LIMITED \\
600619 & SHANGHAI HIGHLY(GROUP)CO.,LTD. \\
600690 & QINGDAO HAIER CO., LTD. \\
600839 & SICHUAN CHANGHONG ELECTRIC CO., LTD. \\
600854 & JIANGSU CHUNLAN REFRIGERATING EQUIPMENT STOCK CO., LTD \\
600983 & HEFEI RONGSHIDA SANYO ELECTRIC CO., LTD \\
\hline & \\
\hline
\end{tabular}

